\title{
Dossiê Pesquisa Aplicada em Comunicação
}

\author{
[...] ]e não ignoro que todas as ilhas, \\ mesmo as conhecidas, são desconhecidas \\ enquanto não desembarcarmos nelas.[...] \\ é necessário sair da ilha para ver a ilha.
} (O Conto da Ilha Desconhecida, José Saramago)

A necessidade de conhecer é inerente à condição humana. Ela é movida por questões de sobrevivência, aprimoramento, desejo ou anseio de compreender o mundo. O ser humano busca incessantemente conhecer e transformar aquilo que o cerca, para além do tecido aparente, seja do outro, da sociedade ou de si mesmo.

O processo de construção do conhecimento científico é atravessado pelas transformações sociais que marcam os diferentes contextos históricos. A realidade delineada por circunstâncias produz demandas de estudos cujos resultados permitem, para além do conhecimento construído, a possibilidades de intervenção. Embora o objeto de pesquisa constitua uma construção do investigador, mediada pelo referencial teórico adotado, o discurso científico decorre de condições sociais concretas de sua elaboração, desenvolvimento e difusão.

Nesse sentido, toda investigação científica é motivada por um problema, uma dúvida ou uma demanda social advinda da realidade empírica (MINAYO, 2001). Embora, nesse processo, seja necessário um primeiro distanciamento do pesquisador, como que "afastar-se da ilha para observá-la", para compreendê-la, a suposta neutralidade científica se esvazia pela necessidade de mediação da visão de mundo do observador, que define inclusive o objeto de estudo, sendo necessário "desembarcar na ilha" para compreendê-la. Desse modo, o processo de investigação é permeado por uma complexa e paradoxal relação entre o sair e adentrar nas "ilhas da realidade" e do conhecimento.

No que concerne à pesquisa em comunicação, cujos objetos de investigação são majoritariamente empíricos, esta deve se situar num contexto que privilegie sua contribuição para a sociedade. Até que ponto uma pesquisa de análise jornalística promove 
o acesso da sociedade aos seus conteúdos? A mídia, em seus diversos formatos, será utilizada para quais propósitos? Como desenvolver estratégias comunicacionais para o enfrentamento de problemáticas contraditórias ao bem comum? Assim, evidencia-se, cada vez mais, a comunicação em diálogo com questões que permeiam outros campos do conhecimento, dada a complexidade dos objetos de investigação que, na contemporaneidade, exige abordagens interdisciplinares. Dessa confluência entre aspectos de ordem científica, institucional e social, vislumbra-se a intervenção social (LOPES, 2003, p.191).

Nas últimas décadas, o cenário da pós-graduação stricto sensu no Brasil é marcada pelo advento dos cursos de mestrado profissional. A produção de conhecimento socialmente relevante, cujos resultados subsidiem possibilidades de aplicação, é aspecto em pauta nos debates sobre ciência e tecnologia nas diferentes áreas do conhecimento. Tradicionalmente, as ciências exatas e da natureza são mais direcionadas à aplicação prática de suas descobertas em relação às pesquisas nas áreas das ciências humanas e sociais.

Contudo, a compreensão dicotômica entre pesquisa básica e aplicada é limitante, uma vez que o empírico e o teórico constituem dimensões cuja interface é necessária ao saber investigativo, cuja interdisciplinaridade tem se mostrado cada vez mais necessária para a apreensão dos fenômenos. Assim, não seria possível desenvolver aplicação prática sem fundamentação teórica. Além disso, a aplicação prática do conhecimento teórico leva a novos questionamentos, que podem ser investigados através de novas aproximações epistemológicas.

O Dossiê Pesquisa Aplicada em Comunicação está inserido nesse contexto. Esta edição reúne artigos com diversos desenhos de investigação que envolvem a pesquisa aplicada enquanto aspecto inerente à inovação para o desenvolvimento da comunicação contemporânea. O objetivo da publicação é a divulgação científica do conhecimento para o desenvolvimento da comunicação no que concerne à natureza aplicada das pesquisas nesse campo.

Vale salientar que foram submetidos para este Dossiê mais de 60 artigos. A avaliação dos estudos baseou-se em um processo criterioso de análise comparativa, a fim de selecionar estudos mais próximos ao escopo do dossiê temático. Com isso, buscou-se uma representação mais ampla possível da diversidade da pesquisa aplicada no campo da comunicação. Os estudos abordam desde referenciais teórico-metodológicos férteis para a pesquisa aplicada, passando por reflexões acerca da temática no campo da comunicação, até artigos que resultam de pesquisas aplicadas.

O primeiro artigo, intitulado A publicidade social sobe e desce o morro, aborda as relações entre comunicação publicitária, práticas de ensino e retorno social. A partir da 
descrição e análise de campanhas realizadas no Morro da Providência, (Rio de Janeiro), pelo Laboratório de Investigação em Comunicação Comunitária e Publicidade Social da Universidade Federal Fluminense, o estudo busca problematizar, histórica e teoricamente, Publicidade Social e engajamento social na Educação Superior.

O texto Pesquisa aplicada em comunicação - O estranhamento da interdisciplinaridade que nos assombra traz uma reflexão que problematiza "a baixa incidência de pesquisas de cunho aplicado no Campo da Comunicação, a partir das origens históricas ligadas ao seu desenvolvimento". Ao utilizar a proposta epistemológica Design Science (DS), demonstra caminhos possíveis a partir de exemplos de cunho aplicado já finalizados e em andamento.

O terceiro artigo, A cartografia como mapa movente para a pesquisa em comunicação, discute os pressupostos basilares da perspectiva cartográfica em comunicação. A autora conclui que um aspecto importante da cartografia é o seu entendimento de método de investigação como criador da realidade, o que tenciona o paradigma da representação. Nas palavras de Kastrup e Passos (2013), a autora coloca que "não se trata de descobrir o que é dado como natureza ou realidade preexistente, mas intervir na realidade e nesse processo fazer emergir a criação. Buscar o conhecimento desse modo, implica, portanto, em transformar a realidade, obter um mundo que está nas mãos do pesquisador e isso envolve um comprometimento ético, político com o ato do conhecimento".

Em Análise cultural de produtos audiovisuais[...], os autores apresentam resultados preliminares de um projeto de pesquisa cujo objetivo é a elaboração de um modelo de análise aplicada, afinado com a tradição dos estudos culturais em sua relação com o campo da Comunicação. Os autores consideram que a apresentação do percurso no âmbito de uma pesquisa aplicada em andamento permite importante contribuição para a área. Nesse sentido, compreendem o audiovisual a partir de um enfoque mais amplo, sob um viés comunicativo, o que possibilita uma sistematização para a realização de pesquisas empíricas.

No artigo Jornalismo guiado por dados como ferramenta de fact-checking[...] discute-se o jornalismo guiado por dados como método central no processo de fact-checking (checagem de fatos). A análise é feita a partir de experiência em um curso de extensão realizado na Faculdade de Biblioteconomia e Comunicação da Universidade Federal do Rio Grande do Sul (UFRGS), que revela limitações e potencialidades do método. Conforme afirmam os autores, o "princípio da transparência está na base, tanto do jornalismo guiado por dados quanto do fact-checking, sendo este, portanto, um dos principais aspectos a justificar a apropriação de suas técnicas pelos sistemas de verificação". 
O texto seguinte, intitulado $O$ design thinking como empatia, experimentação $e$ colaboração na comunicação, traz resultados de uma pesquisa aplicada a partir da experiência dos consumidores. Adota-se como base o design thinking como referência para a formulação de processos de comunicação. O artigo apresenta a aplicação da experiência em uma empresa (missões Junior). "As discussões do artigo relatam as etapas da metodologia aplicada à comunicação, descrevendo o caminho percorrido e as implicações nos processos comunicacionais".

Em Uma metodologia ecológica para análise de bolhas algorítmicas, aborda-se a problemática ético-política da organização de dados em bolhas algorítmicas nos sites de redes sociais, bem como a transformação do maquinismo comunicativo agenciado pelos algoritmos. O foco recai sobre limites e potencialidades de métodos de análise tradicionais na Comunicação, a partir da necessidade de se pensar em ferramentas condizentes com as problemáticas desses espaços de interação. Ao fim, o texto propõe o que classifica como uma metodologia ecológica relacionada à dimensão assignificante da comunicação.

O oitavo artigo deste dossiê traz uma análise da produção do conhecimento nos mestrados profissionais em comunicação no Brasil. Constata-se que esses programas constituem um campo ainda em processo de consolidação no País. Observa-se, ainda, que a interdisciplinaridade e as linhas de pesquisa indicam uma importante interface com a inovação, o que se constitui em um panorama com potencialidades para a produção de conhecimento voltado para a aplicabilidade prática.

O texto Pesquisa aplicada em jornalismo: o desafio da construção do objeto apresenta uma discussão sobre a possibilidade de se fazer pesquisa aplicada no campo do jornalismo, com especial atenção ao objeto científico e à sua construção. $\mathrm{O}$ argumento central reforça que "a aplicabilidade do trabalho de investigação não pode ser forçosamente colocada como objetivo do trabalho a ser realizado, mas, sim, ser uma demanda identificada em meio aos fenômenos jornalísticos", sobre os quais se considera pertinente intervir.

Por fim, o artigo Comunicação política e educação explora, por meio de revisão bibliográfica, experiências internacionais que envolvem a prática da deliberação em escolas e apresenta os passos da primeira experiência voltada para a aprendizagem e o treinamento de capacidades deliberativas no cenário brasileiro. A partir de uma perspectiva interdisciplinar, o texto vislumbra "contribuir com pesquisas comunicacionais que visam à intervenção social no que tange à resolução de conflitos, modelos de discussão colaborativa e convivência democrática no âmbito escolar". 
O conhecimento científico a serviço da sociedade é a essência da pesquisa aplicada. O presente dossiê está inserido nesse contexto. A reunião desses pesquisadores e pesquisadoras, por meio dos seus resultados de investigação, significa muito mais do que uma publicação. Trata-se de um esforço conjunto no processo de consolidação da pesquisa aplicada em comunicação no Brasil, algo nem um pouco simples, sobretudo levando-se em conta a negligência histórica de sucessivos governos em relação aos campos da ciência e tecnologia no País.

Nesse sentido, diante da conjuntura adversa para a produção de conhecimento científico, uma publicação dessa natureza revela algo bem mais ambicioso, que não cabe nos índices de mensuração de produção. O propósito, com a pesquisa aplicada, é contribuir com a construção de um mundo melhor por meio da ciência. Essa é a nossa missão. Boa leitura!

Rebeca Nunes Guedes de Oliveira ${ }^{1}$ Juliano Mendonça Domingues da Silva ${ }^{2}$

\section{Editores do Dossiê Pesquisa Aplicada em Comunicação}

1. Professora do Programa de Mestrado Profissional em Comunicação da Universidade Municipal de São Caetano do Sul

2. Professor do Programa de Pós-graduação em Indústrias Criativas da Universidade Católica de Pernambuco. 